\title{
CENTROS COMERCIALES A CIELO ABIERTO EN LAS CENTRALIDADES TRADICIONALES DEL CONURBANO BONAERENSE
}

\author{
Lorena Vecslir, Luciana Rodríguez \\ CONICET- Instituto de Geografía, UBA \\ lorena.vecslir@conicet.gov.ar, lucianarodriguez@conicet.gov.ar
}

\section{RESUMEN}

Con distintas denominaciones y acentos en determinadas políticas urbanas, los Centros Comerciales a Cielo Abierto (CCCA) han servido como modelo de intervención en numerosas ciudades de EUA y Europa desde los años setenta hasta la actualidad. En Latinoamérica, las propuestas de revitalización y preservación patrimonial de los centros históricos durante los '90 no han ignorado estas experiencias, pero no es hasta esta década que se instala la discusión en torno a las cuestiones relacionadas con su financiamiento e impacto en la actividad económica y mercado de suelo, así como con los modos de gerenciamiento y promoción del comercio de calle frente a la competencia de las grandes superficies comerciales -y también del comercio ilegal-. En este marco y dentro de un programa financiado por el Banco Interamericano de Desarrollo, se han venido formulando desde inicios de los 2000 una serie de acuerdos entre la Confederación Argentina de la Mediana Empresa y diversos municipios del Conurbano Bonaerense, a fin de impulsar la transformación de sus áreas centrales tradicionales bajo el modelo de CCCA. La presente ponencia se propone analizar de manera comparativa estas acciones urbanas: su patrón de distribución territorial, tamaño y tipo de operaciones, grado de realización, actores intervinientes y articulación con otras políticas públicas locales, a fin de reflexionar sobre la "imagen" urbana, perfil comercial y prácticas sociales que éstas promueven, así como sus alcances y limitaciones frente a las diferentes formas y procesos de la centralidad metropolitana, y capacidad de vinculación con otras políticas urbanas de escala territorial.

Palabras clave: Centralidad, Comercio a Cielo Abierto, Estructuración Urbana, Región Metropolitana de Buenos Aires, Identidad

\begin{abstract}
With different names and accents in certain urban policies, the Centros Comerciales a Cielo Abierto (CCCA) have served as model of intervention in numerous cities in USA and Europe since the 1970s to the present. In Latin America, the proposals for revitalization and heritage preservation of historic centers during the ' 90 s have not ignored these experiences, but it is not until this decade that it settled the discussion of issues related to its financing and impact on economic activity and the land market and also the management and promotion of trade in street facing competition from superstores - as well as illegal trade-. Within this framework and in a program financed by the IDB, since the beginning of the 2000 there has been made a series of agreements between the Argentina Chamber of the SME and various municipalities in greater Buenos Aires in order to promote the transformation of their traditional core areas under the model of CCCA. The present paper proposes a comparative analysis about these urban actions: its pattern of distribution territorial, size and type of operations, grade of realization, actors involved and articulation with others local public policies, in order to think about the urban "image", commercial profile and social practices that they promote, as well as their reaches and limitations facing the different forms and processes of metropolitan centrality, and the capacity to link them with other urban policies of territorial scale.
\end{abstract}

Key words: Centrality, Open-air retail, Urban Structuring, Metropolitan Region of Buenos Aires, Identity 


\section{INTRODUCCIÓN}

En el marco de un programa financiado por el Banco Interamericano de Desarrollo (BID), desde inicios de los dos mil, se han venido formulando una serie de acuerdos entre la Confederación Argentina de la Mediana Empresa (CAME) y diversos municipios del Conurbano Bonaerense $(C B)^{1}$ a fin de impulsar la transformación de sus áreas centrales tradicionales bajo el modelo de Centros Comerciales a Cielo Abierto (CCCA).

La sumatoria de estas iniciativas de escala local -que ya involucran 10 de los 24 municipios del $\mathrm{CB}^{2}{ }^{2}$ da cuenta de la implementación cada vez más generalizada, en nuestra región metropolitana, de un tipo de política urbana destinada a intervenir en el mejoramiento de las áreas centrales tradicionales de las principales localidades, justificada en la mayoría de los casos, como respuesta a la progresiva pérdida de atracción de las mismas y la declinación de la dinámica comercial minorista, ante el surgimiento de los shoppings y otras grandes superficies comerciales, así como también en la degradación ambiental, proliferación del comercio ambulante y contaminación visual, abogando siempre al "fortalecimiento de la identidad local".

Las acciones concertadas a partir de estos acuerdos, que operan como alianzas entre los comerciantes, el sector público y diversas organizaciones privadas, se orientan, por un lado, al reordenamiento del espacio público de las principales calles comerciales (peatonalización, cambios de solado, soterramiento del cableado eléctrico, nueva luminaria, códigos de cartelería, etc.) y, por otro, a la instrucción para la promoción comercial (campañas de marketing, eventos culturales, etc.) y capacitación empresarial.

Aunque algunas intervenciones de CCCA se inscriben en el marco de planes urbanos a escala municipal, en general, éstas presentan ciertas dificultades para articularse con el resto de políticas públicas locales en materia de transporte, manejo de residuos, vivienda social, e incluso de espacio público. Tampoco existen ni se registra la intencionalidad de realizar- análisis territoriales más amplios que contemplen estas operaciones a escala de toda la región metropolitana, a fin de vincularlas con políticas sectoriales de movilidad y accesibilidad desde el transporte público (potencial competencia con las grandes superficies comerciales orientadas hacia el automóvil), y que, desde una perspectiva más basta, pongan en discusión las competencias y complementariedades del sistema de centralidades tradicionales en conjunto con los enclaves emergentes del ocio y el consumo, así como con la permanencia y el rol estructurante de antiguos corredores comerciales suburbanos, característicos de nuestra región metropolitana.

Paralelamente, resulta recurrente el uso directo de modelos extranjeros de intervención y gestión, sobre la base de antecedentes de CCCA en su mayoría españoles. En este sentido, la ausencia de un análisis crítico que determine las diferencias estructurales con los lugares específicos de actuación, parecería conducir a un alejamiento del rescate identitario que se persigue como objetivo. Por caso, la eliminación del comercio ambulante como un "estorbo a la vida pública" o bajo el lema de "recuperar la calle para las personas".

Dentro de este marco, se plantean entre otros interrogantes: ¿Qué lugares se eligen para intervenir? ¿Qué tipo de "imagen" urbana y perfil comercial se promueven con estas acciones? ¿Recuperar las calles para quienes? ¿Qué prácticas sociales fomentan las intervenciones? ¿Cuáles son sus alcances y limitaciones frente a las diferentes formas y procesos de la centralidad metropolitana? ¿Qué potencialidades de articulación presentan con las políticas locales y territoriales?

Como primera aproximación a estas cuestiones, la presente ponencia se propone estudiar de manera comparativa las acciones urbanas promovidas por la CAME en el CB. En primer lugar, se buscará rastrear el origen del concepto y relacionar las primeras experiencias de CCCA en EUA y Europa entre los años '70 y '80, con la circulación de ideas hacia Latinoamérica una década más tarde y, en especial, con las iniciativas en la región metropolitana de Buenos Aires desde inicios de los 2000. En segundo término, se realizará un análisis comparado de estas acciones en el CB: su patrón de distribución territorial, tamaño y tipo de operaciones, grado de realización, los actores involucrados y características específicas de intervención y gestión, articulación con otras políticas públicas locales, grados de compromiso de los acuerdos, etc. En base a este análisis, se propone, por último, reflexionar acerca de las transformaciones socio-territoriales

\footnotetext{
${ }^{1}$ Se entiende por Conurbano Bonaerense (CB), el territorio conformado por los 24 municipios que forman la $1^{\circ}$ y $2^{\circ}$ corona de la aglomeración de Buenos Aires y que, en conjunto, comprende un área de $3.630 \mathrm{~km}^{2}$ y una población actual de aproximadamente 10 millones de habitantes.

${ }^{2}$ Con distinto grado de concreción, existen iniciativas de CCCA en los municipios de Morón, Lomas de Zamora, San Fernando, San Isidro, Tigre, Vicente López, Moreno, Hurlingham, Tres de Febrero y San Miguel. Fuera del CB, en la tercera corona metropolitana, también se registran acuerdos con los municipios de Pilar y Luján.
} 
promovidas en relación a aquellas cuestiones que quedan relegadas frente a las estrategias de promoción comercial y la búsqueda de un ambiente urbano "atractivo" para el visitante.

\section{ORIGEN DEL CONCEPTO Y PRIMERAS EXPERIENCIAS DE CCCA Transferencias hacia Latinoamérica y la región metropolitana de Buenos Aires}

Si bien el término Centro Comercial a Cielo Abierto (CCCA) puede variar según el lugar geográfico donde se desarrolle, ${ }^{3}$ en general alude a dos cuestiones sustanciales: la centralidad del área en cuestión respecto de la aglomeración donde se asienta, y el carácter descubierto de los comercios involucrados, en oposición a la concentración de los mismos bajo una única superficie cubierta -como los shopping malls, galerías comerciales, grandes tiendas, etc.- (Molinillo Jimenez, 2001).

Aunque rastrear el origen de los CCCA es difícil debido a la falta de convención sobre su nombre y sistematización sobre sus implicancias, existe consenso sobre su primera manifestación en los años sesenta en Canadá. Allí, un grupo de pequeños empresarios lograron generar una legislación para el desarrollo de una entidad privada y autónoma, que imponía impuestos a los dueños de los comercios de un determinado sector de la ciudad para financiar tareas de revitalización urbana (Hoyt, 2006; Hoyt \& Gopal-Agge, 2007). Sin embargo, fue en Estados Unidos diez años después, donde cobró más fuerza debido, entre otras causas, al declive de los centros urbanos tradicionales frente al acelerado sprawl del crecimiento residencial y el desarrollo de nuevos enclaves y formatos comerciales en la periferia de las ciudades. A estos factores, se sumó la dificultad de financiamiento de los gobiernos locales a causa de la disminución de la base tributaria, lo que derivó en el crecimiento de las alianzas público-privadas para asumir las operaciones de revitalización y mantenimiento urbano (Hoyt \& Gopal-Agge, 2007). Así, surgieron los "Distritos de Mejora de Negocios" o Business Improvement Districts (BIDs), ${ }^{4}$ definidos como un grupo de propietarios y/o comerciantes que acuerdan proveer de un grado adicional de servicios (seguridad, limpieza, promoción de eventos, asistencia social, etc.) a un área geográfica específica, a través de la imposición de impuestos añadidos a todas sus propiedades y/o negocios (Mitchell, 2001). Según Bratos Martin, la característica fundamental de este tipo de gestión reside en que "una vez aprobado el BID, mediante un convenio con el Ayuntamiento, normalmente de cinco años, todos los propietarios comerciales de la zona a que hace referencia se convierten en miembros, estén o no de acuerdo con la formación del mismo. Por tanto, quedan obligados a abonar el recargo obligatorio acordado que, en el caso estadounidense, recaerá sobre los propietarios y no sobre los arrendatarios" (Bratos Martín, 2013:284).

La primera "transferencia de políticas" (policy transfer) ${ }^{5}$ vinculadas a los BID desde Estados Unidos a Europa se realizó a través del Reino Unido. En este país, las ideas acerca del nuevo modelo de gestión encontraron un campo fértil de desarrollo dada la experiencia previa en esta temática, adquirida a través de la figura de "Administración del Centro Urbano" o Town Centre Management (TCM). La diferencia de los TCM con los BID radicaba en dos cuestiones: el área de aplicación no estaba claramente definida y la financiación se obtenía a través de contribuciones voluntarias tanto del sector público como del privado. Fue justamente este último factor el que dio lugar a la transformación de los TCM por la figura de los BID, buscando corregir el beneficio que ciertos actores obtenían indirectamente sin efectuar ningún tipo de aportaciones.

Con algunas variaciones, el modelo se expandió posteriormente por otros países como Alemania y Holanda. En España, el instrumento utilizado fue el de Centros Comerciales Abiertos (CCA), fortalecido por el desarrollo de legislaciones específicas dentro algunas comunidades autónomas como Extremadura o Andalucía (Bratos Martín, 2013). De acuerdo a la definición expresada en el I Congreso Nacional de Centros Comerciales Abiertos (Huelva, 2000), los CCA constituyen una "(...) fórmula de organización comercial, con una imagen y estrategia propia, que cuenta con la implicación de todos los agentes de un área delimitada de una ciudad, con una concepción global de oferta comercial, servicios, cultura y ocio" (Asociación Provincial de Empresarios de Comercio de Huelva, 2000).

\footnotetext{
${ }^{3}$ En el artículo "Centros comerciales de área urbana. Estudio de las principales experiencias extranjeras" (Molinillo Jimenez, 2001), puede encontrarse un desarrollo detallado de los nombres que estas asociaciones adoptan en diferentes países del mundo.

${ }^{4}$ De acuerdo a Gopal (2003 en Bratos Martín, 2013) las actividades que involucran los BID pueden dividirse en tres grupos principales, donde cada uno sienta las bases para el desarrollo del siguiente: mejora del entorno (mantenimiento y limpieza del área y consolidación de la seguridad), acciones de marketing del consumidor y acciones que tratan de asegurar la sostenibilidad del BID a largo plazo.

${ }_{5}^{5}$ Término que describe la transferencia de conocimientos y prácticas empleadas en un contexto determinado hacia otro contexto, en donde la temática de revitalización urbana se está volviendo muy popular debido, entre otras causas, al poco involucramiento que el sector público está teniendo en su desarrollo (Hoyt, 2006). El mismo autor advierte sobre el problema que puede representar el desarrollo de políticas en base a evidencia subjetiva, en lugar de ponderarlo en relación a la situación económica, la legislación y otras diferencias entre los contextos de exportación e importación.
} 
Por tanto, mientras que los BIDs norteamericanos se configuran, ante todo, como un modelo de gestión capaz de dotar a una zona de una serie de servicios adicionales a los ya provistos por la Administración Pública a partir de la imposición de una cuota obligatoria; los CCA españoles hacen recaer sobre el sector público la principal responsabilidad de financiamiento, contemplando dos tipos de actuaciones: aquellas que conducen a la renovación de las estructuras para mejorar el atractivo comercial de la zona, y aquellas que potencian el asociacionismo y las actuaciones conjuntas del pequeño comercio (Molinillo Jimenez, 2001). Las primeras, generalmente enmarcadas dentro de planes integrales de mejora o rehabilitación de centros históricos, conllevan operaciones vinculadas a la mejora del espacio público y la creación de una imagen unitaria, a lo que además se intenta sumar condiciones más independientes de gerenciamiento, a través de la conformación de un consorcio responsable de llevarlas a cabo.

En América Latina, paralelamente al desarrollo de estas experiencias, las áreas centrales tradicionales de las grandes metrópolis sufrían importantes transformaciones: la acelerada pérdida de sus funciones de comando y el traslado del poder económico hacia nuevos centros corporativos periféricos a la ciudad compacta, el progresivo deterioro del patrimonio edilicio, la proliferación de comercio popular o de tipo ambulante, episodios de tugurización residencial, etc. En este marco, y desde una concepción del "centro" como el lugar histórico/fundacional donde se establecieron las primeras instituciones y equipamientos públicos en torno a la plaza como principal lugar representativo (Vecslir \& Elimbaum, 2016), las operaciones de mejora del espacio público, peatonalización, expulsión del comercio callejero, recuperación del patrimonio arquitectónico y promoción de usos culturales y turísticos, resultaron políticas comunes en la rehabilitación de los centros históricos de diversas metrópolis (Lima, Bogotá, Panamá, Quito, México) durante los '90. ${ }^{6}$ Bajo un enfoque "monumentalista" del centro, estas intervenciones se apoyaron en la voluntad de recuperación de determinados valores morfológicos y simbólicos, como "memoria" de unas funciones cívicas y de gobierno, y de una población residente, que en la mayoría de los casos, desde inicios del siglo XX, fue perdiendo intensidad ininterrumpidamente (Carrión, 2005). ${ }^{7}$

Este tipo de políticas tuvo la virtud de poner en valor la riqueza patrimonial de los centros históricos desde la acción pública, pero no ha sido hasta esta década que se ha instalado la discusión en torno a las cuestiones relacionadas con su financiamiento e impacto en la actividad económica y mercado de suelo, así como con los modos de gerenciamiento y promoción del comercio de calle frente a la competencia de las grandes superficies comerciales -y también del comercio ilegal-. En este sentido, resultan clave el rol de organismos como el Banco Interamericano de Desarrollo (BID), la Unesco, la Junta de Andalucía -y otras fuentes de financiamiento nacionales e internacionales-. Asimismo, según Carrión (2007), cobran vital importancia: el sector del turismo, que a su vez arrastra otros servicios como los culturales, hoteleros, comerciales, inmobiliarios, etc.; la rehabilitación edilicia que dinamiza el sector de la construcción y el mercado inmobiliario; y el comercio (formal e informal), como protagonista indiscutible en el proceso de transformación.

Desde esta perspectiva, las ventajas de "recuperar la identidad y fortalecer la centralidad histórica", comienzan a vincularse con los denominados procesos de gentrificación, turistificación, e incluso boutiquización de las áreas centrales "que eliminan la población residente para dar paso a los usos del suelo más rentables y exclusivos (comercios, hoteles, restaurantes, bajo la lógica boutique)" (Carrión, 2007:10). Como ya nos anunciaba Jane Jacobs (1961), la acentuación de estos usos puede dar lugar a procesos de "autodestrucción de la diversidad", expulsando actividades de servicios y comercio cotidiano que no pueden competir con el nuevo valor de suelo. De igual manera, los desplazamientos comerciales y económicos han sido ampliamente señalados en el contexto latinoamericano, donde los proyectos de restauración y patrimonialización de los centros urbanos históricos han implicado la expulsión de los vendedores ambulantes, así como indigentes y toxicómanos, con el fin de estimular la atracción y los negocios turísticos (Lorenzen Martiny, 2015:282).

En el caso de Buenos Aires, y a diferencia de otras metrópolis latinoamericanas (Santiago, San Paulo, Bogotá, México DF, etc.), el comercio de calle ha resistido los embates -tardíos pero potentes- del shopping center y las grandes superficies comerciales, concentrando en este formato los porcentajes más altos del comercio minorista. ${ }^{8}$ Esto es así en la Capital Federal, con un intenso dinamismo comercial en las principales avenidas

\footnotetext{
${ }^{6}$ Ver, por ejemplo, la compilación de trabajos editada por Fernando Carrión (2001) que incluye estudios de caso sobre la preservación de centros históricos en América Latina y reflexiones teóricas acerca del paso de la conservación monumental a la rehabilitación urbana integral, las instituciones, los actores y los temas emergentes en la conservación patrimonial.

${ }^{7}$ Cabe citar, por ejemplo, el programa "Volvamos al centro", impulsado en los años noventa y génesis del llamado "Modelo Lima". La campaña estaba dirigida a los descendientes de la oligarquía limeña que había abandonado el centro en los años cuarenta, como si el centro estuviera vacío o "perdido" (Ludeña, 2002).

8 En Argentina, los locales a "la calle" o "a cielo abierto" concentran el $75 \%$ de las ventas (http://www.areasdigital.com.ar/nota.php?id=24369) y, según un estudio elaborado por la plataforma Paseos de Buenos Aires, en la ciudad capital este
} 
e intercambiadores de transporte, y donde la proliferación de malls y nuevos centros comerciales no parece haber afectado la estructura comercial a cielo abierto de los distritos tradicionales (Once, Belgrano, Flores, calle Florida, Av. Santa Fe, Recoleta) ni de los nuevos distritos de la moda y el diseño (Av. Córdoba, Palermo, Av. Avellaneda, San Telmo, etc.) (Ciccolella, Vecslir, \& Baer, 2015). En el CB, en cambio, el comercio de calle no siempre ha ganado la batalla contra los nuevos centros del ocio y el consumo, y la vitalidad de las áreas centrales tradicionales -e incluso su pervivencia como imaginario de centralidad- es más discutible, caso por caso.

En este marco, con el objetivo de promover el comercio de calle frente a la competencia de las nuevas superficies comerciales -pero sobre todo del comercio ilegal (manteros y "saladitas") ${ }^{9}$-, desde el 2000 la CAME, mediante la firma de un convenio con el BID y el Fondo Multilateral de Inversiones (FOMIN) lleva adelante un programa de fortalecimiento al comercio minorista. ${ }^{10} \mathrm{~A}$ través de este instrumento, se han planteado proyectos de renovación bajo el modelo de CCCA, en las calles más emblemáticas del microcentro de la CABA, como la peatonal Florida y la avenida Corrientes, en el barrio de Palermo, en los outlets de calle Aguirre o avenida Córdoba, en el eje Warnes especializado en repuestos para autos, etc.

Asimismo, desde su inicio, estos acuerdos han involucrado áreas urbanas externas al ámbito de la ciudad capital, ${ }^{11}$ superando el límite de la Avenida General Paz para promover el desarrollo de CCCA a lo largo de antiguas avenidas comerciales o centralidades tradicionales de diversas localidades del CB. Allí, existen iniciativas en centralidades poco consolidadas (ej. en algunas localidades de Tres de Febrero) o con indicios de degradación debido a las nuevas opciones residenciales de baja densidad, el cambio de formatos y patrones de consumo, y el incremento de la movilidad privada (ej. en algunas localidades de Tigre y Vicente López); pero, sobre todo, se implantan en centros tradicionales de la primera y segunda corona metropolitana, en relación a importantes estaciones ferroviarias como Lomas de Zamora en el Sur, Morón en el Oeste, San Isidro, Vicente López y Tigre Centro en el norte del conurbano. Asimismo, suelen acompañar procesos recientes de crecimiento residencial en altura, manifestando la existencia de una demanda inmobiliaria que se inclina por algunos subcentros tradicionales que renuevan parte de sus funciones (ej. Lomas de Zamora, San Miguel, Tigre Centro). Aunque sin servicios complejos, también se recupera el comercio, aparecen locales de franquicias y usos comerciales más sofisticados, vinculados a la gastronomía especializada, cafés boutique, diseño e indumentaria de primeras marcas y oficinas bien equipadas (Ciccolella, Vecslir, \& Baer, 2015).

Los estados de planeamiento (de la zonificación al plan urbano o estratégico) y niveles de propuestas (programas y proyectos urbanísticos) para las áreas centrales varían según el caso, así como la historia en las escisiones o subdivisiones de los términos municipales, el perfil más o menos turístico de las localidades, el grado de especialización comercial, la proximidad a la ciudad central y tipo de accesibilidad, etc., son determinantes del tipo de centralidad a intervenir.

Por tanto, a pesar de la tradicional visión monocéntrica, que contrapone una ciudad capital, asociada a la idea de urbanidad a un Conurbano construido sobre una cuadricula uniforme, estable e infinita, sin contrapuntos ni variaciones (Vecslir \& Elimbaum, 2016), existen múltiples formas de centralidad que de a poco comienzan a ser objeto de reflexión por parte de los estudios urbanos, y de las políticas públicas desde los gobiernos locales, entre ellas los CCCA de los que nos ocuparemos en esta ponencia.

\section{UN ANÁLISIS COMPARADO DE LAS INICIATIVAS EN EL CONURBANO BONAERENSE}

Como se señala anteriormente, en Argentina, el desarrollo de CCCA ha tenido como principal promotor a la CAME, organización que nace en 1999 con el fin de fortalecer y mejorar el desempeño de las pymes del sector comercial y de servicios. Como se señalaba anteriormente, a partir de un convenio firmado con el BIDFOMIN en el 2000, se crea dentro del mismo organismo, la Federación de Centros Comerciales a Cielo

porcentaje se eleva a un $82,6 \%$, relegando un $17,3 \%$ de facturación a los shoppings. Muy distinto es el caso de, por ejemplo, los Estados Unidos, en donde sólo el 30\% de los ingresos proviene de los locales pequeños. (http://www.paseosdebuenosaires.com.ar/)

${ }^{9}$ Se conoce por "mantero" a la persona que se dedica a la venta callejera en una plaza o en la vía pública, generalmente sin permiso, poniendo encima de una manta los productos a la venta. Las "saladitas" son complejos feriales (de menor tamaño que la Feria La Salada, ubicada en el partido de Lomas de Zamora), que basan su funcionamiento en la comercialización de productos de marcas apócrifas.

${ }^{10}$ En 2006, en una jornada de evaluación de la primera fase del programa, la CAME aseguraba haber brindado capacitación a 30.000 personas, asistencia técnica a 30 proyectos asociativos y a 35 CCCA en diferentes ciudades argentinas (http://uww.redcame.org.ar).

${ }^{11}$ La primera experiencia del PROCOM, cuyo acuerdo data del 2000 y la ejecución de la primera fase del 2002 , es en el municipio de Morón. 
Abierto, Cascos Urbanos y Centros Históricos (FCCA), responsable del Programa de Competitividad de las Pymes en Centros Comerciales a Cielo Abierto (Procom). En el contexto de este programa, la CAME realiza foros nacionales e internacionales sobre ciudad, comercio y turismo, ${ }^{12}$ y organiza anualmente visitas de dirigentes empresarios y funcionarios municipales a ciudades españolas consideradas como casos exitosos de desarrollo y gestión de CCA (Málaga, Valencia, San Sebastián, Villaviciosa- Asturias, Bilbao, Vitoria y Pamplona, entre otras).

Con base a estos antecedentes, el CCCA es definido como "una organización de comerciantes y otras empresas de servicios que trabajan, asociativamente, en la planificación de la promoción comercial, dentro de una estrategia urbana, en vistas a lograr una identidad propia y distintiva que les permita mejorar los flujos de potenciales compradores, revitalizando los cascos urbanos, y contribuyendo a la jerarquizar la oferta comercial de la ciudad" (Antonione, 2014). Siguiendo el modelo español, existen cuatro aspectos que se consideran esenciales para el desarrollo de un proyecto de CCCA: propuestas de mejoramiento urbano; planes de promoción comercial; plan de identidad y comunicación; y esquema de dirección y gestión.

Sin embargo, aunque en la anterior definición parezca relativizarse el rol de la administración pública en pos de un fuerte asociacionismo de empresarios, en todos los ejemplos analizados dentro del CB, los respectivos gobiernos municipales han sido los mayores responsables en la ejecución y financiamiento de los proyectos. Así, de los cuatro elementos que desde el punto vista teórico deben integrar un CCCA, en general, solo se han desarrollado las propuestas de urbanización del espacio público, y de animación y promoción comercial, fases durante las cuales la CAME actúa como una especie de asesor de la Municipalidad, las asociaciones de empresarios (cámaras de comercio e industria), y eventualmente, otras organizaciones públicas y privadas (entes de turismo, colegios profesionales, entidades financieras, etc.). Luego de estos estadios, no suelen configurarse entes de gestión, registrándose solo un caso de gerenciamiento a través de la formación de un consorcio ad hoc: el Paseo San Miguel en el municipio homónimo.

Pero más allá de los actores involucrados y otros aspectos de gestión, cada uno de los diez acuerdos estudiados goza de especificidades que hemos intentado plasmar de manera sintética en la siguiente tabla (ver tabla 1, en elaboración), donde se recogen los principales aspectos relativos a: localización o distribución geográfica, año del acuerdo, área afectada, agentes intervinientes, objetivos, tareas a desarrollar, fechas y grado de realización, instrumentos urbanísticos asociados, y otras operaciones en la centralidad.

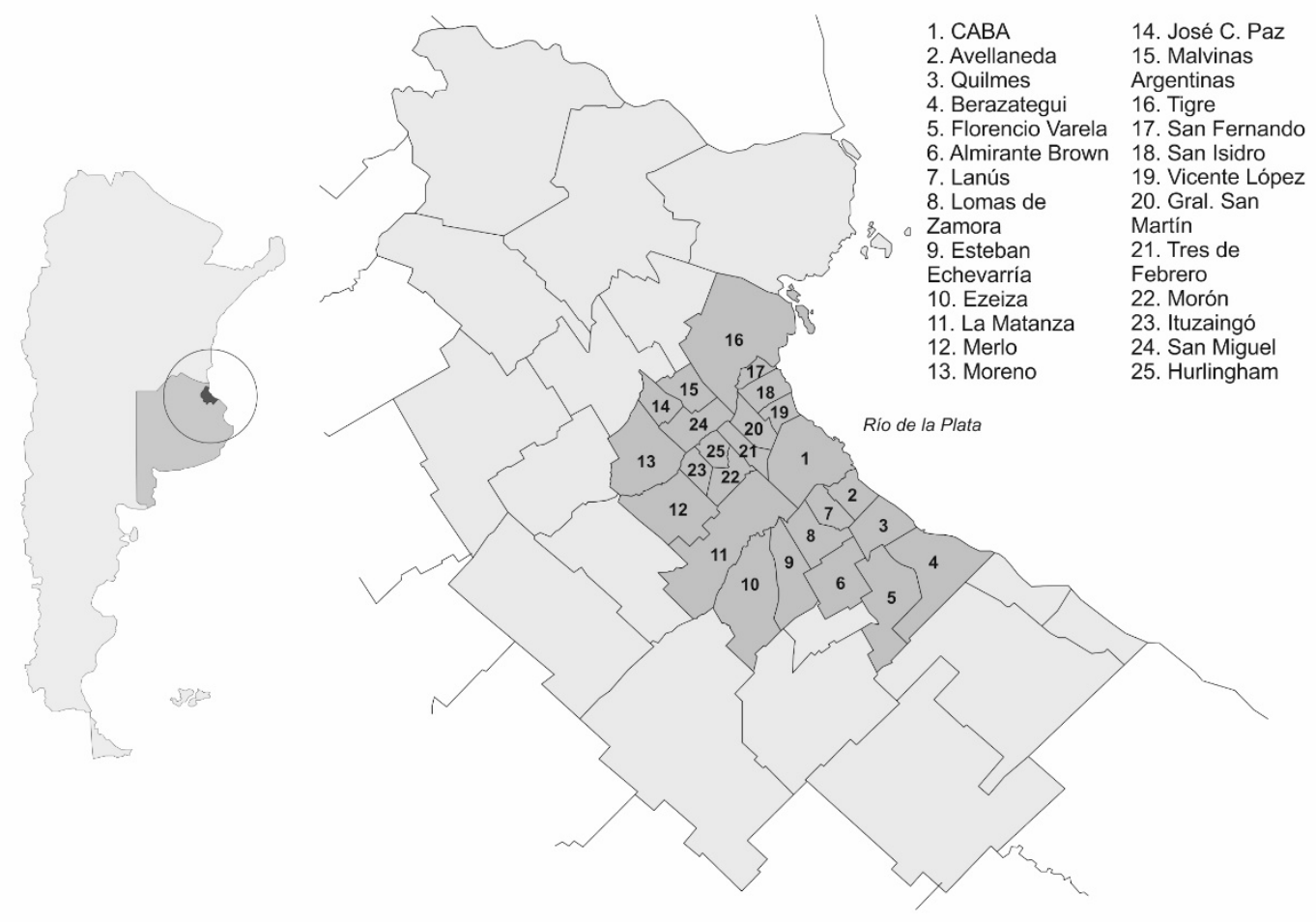

Figura 1. Conurbano Bonaerense

Fuente: Elaboración propia

${ }^{12}$ El Primer Congreso Nacional sobre Experiencias en Desarrollo de Centros Comerciales a Cielo Abierto se realizó en setiembre de 2006 en Villa Mercedes, San Luis. 


\begin{tabular}{|c|c|c|c|c|c|c|c|c|}
\hline \multicolumn{9}{|c|}{ Centros Comerciales a Cielo Abierto en el conurbano bonaerense } \\
\hline $\begin{array}{l}\text { Unicación/ } \\
\text { Nombre }\end{array}$ & $\begin{array}{l}\text { Año del } \\
\text { acuerdo }\end{array}$ & Área & Agentes intervinientes & Objetivos & Tareas a desarrollar & Fecha y grado de realización & $\begin{array}{c}\text { Instrumentos urbanísticos } \\
\text { asociados }\end{array}$ & \begin{tabular}{|c|} 
Otras \\
operaciones \\
en el centro
\end{tabular} \\
\hline $\begin{array}{l}\text { Localidad: Morón } \\
\text { (Morón) } \\
\text { Centro } \\
\text { Comercial a } \\
\text { Cielo Abierto } \\
\text { 1era. Etapa } \\
\text { (CCCAM) }\end{array}$ & 2000 & \begin{tabular}{|c|} 
Área determinado por las \\
calles: Mendoza hasta \\
Independencia, Machado \\
hasta D.F. Sarmiento, San \\
Martin hasta R... del \\
Uruguay, Buen Viaje hasta \\
D.F. Sarmiento \\
Total: 21 manzanas
\end{tabular} & \begin{tabular}{|c|} 
Municipalidad de Morón; \\
Asociaición Comerciale endustrial \\
de Morón (ACIM), CAMEy \\
PROCOM. \\
Financiamiento: Banco \\
Interamericano de Desarrollo
\end{tabular} & \begin{tabular}{|c|} 
Reacondicionamiento de los ejes \\
comerciales del centro, \\
remodelación de plaza San Sartín \\
y construcción de Plazal a Roche, \\
contemplando la restructuración \\
de las manzanas que rodean la \\
estacion de ferrocarril.
\end{tabular} & \begin{tabular}{|c|} 
Obras de mejoramiento y ensanche de \\
vereda, construction de espacios para \\
equipamiento, dársenasas para \\
estacionamiento, colocación de \\
luminarias y construcción de conducto \\
pluvial \\
Ampliación de veredas e instalación de \\
nuevos refugios de colectivos y \\
luminarias. \\
\end{tabular} & \begin{tabular}{|c|} 
2002-2003 Calle Belgrano del 0 al 300 \\
2004 Plaza La Roche \\
2006 Plaza San Martin \\
2011 Calle Ammirante Brown (entre San \\
Martin y 9 de Julio) \\
2015 Areas entre Carlos Casares y $2^{\mathrm{a}}$ \\
Rivadavia c calle Timbúes (Castelar) \\
2016 Firma de un nuevo convenio para \\
intervenir en otros centros comerciales \\
del municipio \\
\end{tabular} & \begin{tabular}{|c|} 
Proyecto para el Area Central de \\
Morón (ACM) \\
Plan de Desarrollo \\
Estratégico 2020 \\
(2005) \\
Plan de CCCA para otras \\
localidades: \\
Castelar, Haedo \\
\end{tabular} & $\begin{array}{c}\text { Traslado del Club } \\
\text { Deportivo Morón y } \\
\text { construcción de } \\
\text { un polo comercial } \\
\text { y recreativo }\end{array}$ \\
\hline $\begin{array}{l}\text { Localidad: Don } \\
\text { Torcuato } \\
\text { (Tigre) } \\
\text { CCA Tigre }\end{array}$ & 2009 & \begin{tabular}{|c|} 
Centro Comercial de \\
Amirante Brown, el \\
Triunvirato, el de la Ruta \\
202, Riobamba y Los Pinos \\
Total. 8 cuadras
\end{tabular} & 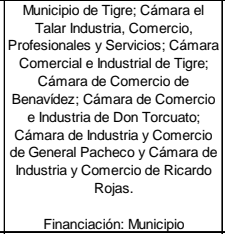 & $\begin{array}{c}\text { Generar las condiciones para que } \\
\text { los centros comerciales de Tigre } \\
\text { luzcan en buen estado y brinden a } \\
\text { los vecinos sas condiciones } \\
\text { necesarias para circular y realizar } \\
\text { sus compras diarias. }\end{array}$ & $\begin{array}{c}\text { Estética unificada: cambio de } \\
\text { materialidad de las veredas, farolas, } \\
\text { palmmeras, rampas para discapacitados, } \\
\text { mobiliario urbano como bancos, } \\
\text { bicicicteteros. Entubamiento para que no } \\
\text { haya agua en los cordones. } \\
\text { Reordenamiento del tránsito, } \\
\text { estacionameintos, nuevos nodos de } \\
\text { acceso. }\end{array}$ & $\begin{array}{c}2011 \text { Calle Almirante Brown, entre Ruta } \\
\text { } 202 \text { 2 AvV. Def Irabajo } \\
2013 \text { Calle Almirante Brown, entre Ruta } \\
202 \text { y Av. Del Trabajo/ / Riobamba entre } \\
\text { Avear y Chile } \\
2015 \text { Calle Campos entre Reconquistay } \\
\text { Estrada }\end{array}$ & $\begin{array}{l}\text { Plan de CCCA para otras } \\
\text { localidades: } \\
\text { Tigre centro (sin información) } \\
\text { EI Talar (2015) } \\
\text { Pacheco (2013) } \\
\text { Los Troncos (2013) } \\
\text { Ricardo Rojas (2011) } \\
\text { Benavidez (2009) }\end{array}$ & $\begin{array}{l}\text { Nuevo } \\
\text { Polideportivo a } \\
200 \text { metros del } \\
\text { centro }\end{array}$ \\
\hline $\begin{array}{c}\text { Localidad: San } \\
\text { Fernando } \\
\text { (San Fernando) } \\
\text { CCA San } \\
\text { Fernando }\end{array}$ & 2011 & \begin{tabular}{|c|} 
Calle Constitución, entre \\
Plaza Mitre y Plaza arros \\
Pellegrini \\
Total: 10 cuadras
\end{tabular} & \begin{tabular}{|} 
Municpalidad de San Fernando; \\
Cámara de San Fernando de \\
Industria Comercio y Servicios \\
(CASAFICO); Cámara de \\
Comercio, Industriay A Actividades \\
Independientes de Virreyes y \\
CAME \\
Financiación: Municipio
\end{tabular} & \begin{tabular}{|c|} 
Fortalecimiento de la \\
competitividad de las PYMES \\
dedicadas al comercio minoristay \\
a la prestación de servicicis. \\
Desarrollo y promoción de los \\
principales ejes comerciales y de \\
servicios de San Fernando.
\end{tabular} & 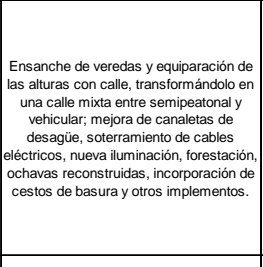 & 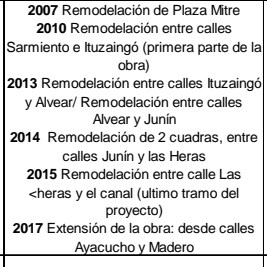 & $\begin{array}{l}\text { Programa para el área central } \\
\text { (2005) } \\
\text { Plan Estratégico (2007) }\end{array}$ & $\begin{array}{l}\text { Remodelación } \\
\text { Plaza Mitre }\end{array}$ \\
\hline $\begin{array}{c}\text { Localidad: San } \\
\text { Isidro (San Isidro) } \\
\text { Comercio a } \\
\text { Cielo Abierto }\end{array}$ & 2011 & \begin{tabular}{|c|} 
Calle Belgrano, entre \\
Centenario y las Cinco \\
Esquinas, y su continuacion \\
por calle enueve de Julio \\
hasta Libertador \\
Total: 10 cuadras \\
\end{tabular} & \begin{tabular}{|c|} 
Municipalidad de San Isidro; \\
Cámara de Comercio e endustria \\
del Partido de San Isidro; Colegio \\
de Arquitectos Distrito IV; CAME \\
Financiación: no especifica
\end{tabular} & \begin{tabular}{|c|} 
Revalorización del área central, \\
que a su vez redundará en la \\
promoción de la actividad \\
comercial y la atracción turistica
\end{tabular} & 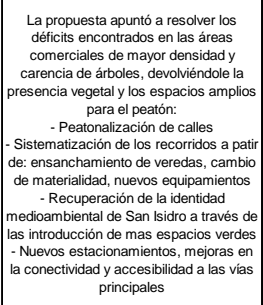 & \begin{tabular}{|c|}
2013 Concurso de Ideas no vinculante \\
convocado por la Municipalidad para \\
reestructurar el Centro Comercial de San \\
Isidro/ Resultados del Concurso de Ideas \\
no vinculante convocado por Ia \\
Municipalicad para reestructurarar el Centro \\
Comercial de San Isidro \\
2014 Primera etapaa intervención \\
urbanistica en las calles 9 de Julio, \\
Belgrano y Acassuso
\end{tabular} & No se encontró información & $\begin{array}{c}\text { No se encontró } \\
\text { información }\end{array}$ \\
\hline 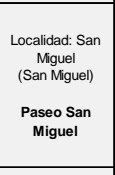 & 2011 & \begin{tabular}{|c|} 
Area comprendida entre las \\
calles Sarmiento, conesa, \\
D'Elia y Roca \\
Actualmente desarrollado \\
sobre Av. Perón \\
Total: 10 cuadras
\end{tabular} & $\begin{array}{c}\text { Municipio y la Cámara de } \\
\text { Comercio e Industria local, a } \\
\text { través de los cuales se crea el } \\
\text { Consorcio Asociativo "Paseo San } \\
\text { Miguel" } \\
\text { Financiación: no especifica }\end{array}$ & $\begin{array}{c}\text { Ser competitivos en un escenario } \\
\text { comercial cambiante, } \\
\text { especialmente ante la incipiente } \\
\text { preferencia del péblico por las } \\
\text { grandes superficies e } \\
\text { hipermercados. }\end{array}$ & \begin{tabular}{|} 
Ensanchamiento de veredas, \\
incoroporación de bancos, luminaras, \\
estacionamientos para bicicletess, cestos \\
de basura y rampas para personas con \\
movilidad reducida. Soterramiento de \\
cables. Reordenamiento del tránsito \\
vehicular, nuevos refugios de colectivos.
\end{tabular} & \begin{tabular}{|c|}
2011 Remodelación calle Sarmiento \\
entre Rocay Conesa \\
2013 Aguas danzantes en Plaza \\
Carretas/ Ciclo "Esquinas culturales" \\
sobre Av. Perón \\
2015 Remodelación calles Sarmiento, \\
Rocay Conesay y calles ltalliay yribulato \\
2016 Estacionamiento medido en el \\
"Paseo San Miguel" \\
\end{tabular} & $\begin{array}{c}\text { Plan "Corredor Aeróbico Municipal" } \\
\text { de Avenida Francia }\end{array}$ & $\begin{array}{c}\text { No se encontró } \\
\text { información }\end{array}$ \\
\hline $\begin{array}{l}\text { Localidad: Lomas } \\
\text { de Zamora } \\
\text { (Lomas de } \\
\text { Zamora) } \\
\text { CCA Lomas de } \\
\text { Zamora } \\
\end{array}$ & $\begin{array}{l}2012 \\
2016\end{array}$ & \begin{tabular}{|c|} 
Peatonal Laprida, entre Av. \\
Meeks y Av. Hipolito \\
Yrigoyen \\
Total: 3 cuadras
\end{tabular} & \begin{tabular}{|c|}
$\begin{array}{c}\text { Municipalidad de Lomas de } \\
\text { Zamora; Cámara Regional de } \\
\text { Comercio e Industria de Lomas de } \\
\text { Zamora }\end{array}$ \\
$\begin{array}{c}\text { Financiación: fondos del plan "Más } \\
\text { Cerca", impulsado por el Gobierno } \\
\text { de la Nación }\end{array}$ \\
\end{tabular} & \begin{tabular}{|c|} 
Embellecer y dotar de \\
infraestructura a la peatonal \\
Laprida, principal arteria a comercial \\
de la ciudad.
\end{tabular} & $\begin{array}{c}\text { Reducción de la contaminación visual } \\
\text { para que la peatonal este limpia, } \\
\text { incorporación de nuevas lumininarias y } \\
\text { áreas de descanso, además de trabajos } \\
\text { de bacheo y pavimentación. }\end{array}$ & 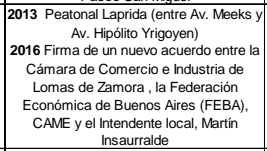 & No se encontró información & $\begin{array}{c}\text { Obras en calle } \\
\text { Boedo }\end{array}$ \\
\hline $\begin{array}{l}\text { Localidad: Munro } \\
\text { (Viente López) } \\
\text { cCA Munro }\end{array}$ & 2014 & $\begin{array}{l}\text { Av. Mitre, entre calles Vélez } \\
\text { Sarfield y Marconi } \\
\text { Total: } 2 \text { cuacras }\end{array}$ & $\begin{array}{c}\text { Cámara Empresaria, la } \\
\text { Municipalidad de Vicente López y } \\
\text { CAME, a través del PROCOM. } \\
\text { Financiación: no especifica }\end{array}$ & \begin{tabular}{|c|} 
Renovar de manera integral el \\
centro comercial tradicional, \\
buscando una mejor experiencia \\
para el vecino en el paseo de \\
compras, al mismo tiempo que los \\
comerciantes aumentan su \\
actividady e el desaralollo de esas \\
zonas se ve favorecido.
\end{tabular} & 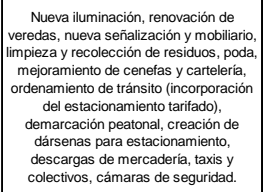 & $\begin{array}{l}\text { 2014-2015 Av. Mitre desde Velez } \\
\text { Sarsfield hasta Marconi }\end{array}$ & $\begin{array}{l}\text { Plan de CCCA para otras } \\
\text { localidades: } \\
\text { Bajo de Vicente López } \\
\text { La Lucila } \\
\text { Villa Martinelli }\end{array}$ & $\begin{array}{c}\text { Centro Comercial } \\
\text { del Bajo de } \\
\text { Vicente López }\end{array}$ \\
\hline $\begin{array}{l}\text { Localidad: Moreno } \\
\text { (Moreno) }\end{array}$ & 2016 & $\begin{array}{l}\text { Calle Independencia } \\
\text { Total: no especifica }\end{array}$ & \begin{tabular}{|c|} 
Confederación de la Mediana \\
Empresa (CAME); Banco \\
Provincia; Unión Empresaria de \\
Moreno; PROCOM; Federación \\
Económica de Buenos Aires \\
(FEBA); Unión de Comerciantes \\
de Moreno \\
Financiación: no especifica \\
\end{tabular} & $\begin{array}{c}\text { Promover una mayor integración y } \\
\text { mejora continua de la calidady } \\
\text { competitividad en la ona án } \\
\text { del municipio. } \\
\text { Revalorizar la identidad social, } \\
\text { comercial, edilicia e historicica. }\end{array}$ & No especifica & Etapa de proyecto & $\begin{array}{l}\text { Proyecto de Recuperación del } \\
\text { Centro de Moreno } \\
(2015)\end{array}$ & \begin{tabular}{|c|}
$\begin{array}{c}\text { No se encontró } \\
\text { información }\end{array}$ \\
\end{tabular} \\
\hline $\begin{array}{l}\text { Localidad: } \\
\text { Hurlingham } \\
\text { (Hurlingham) }\end{array}$ & 2016 & \begin{tabular}{|c|} 
Area del centro comercial \\
(no especifica calles)
\end{tabular} & \begin{tabular}{|c|} 
La Federación Económica de la \\
Provincia de Buenos AAres (FEBA), \\
la Confederación Argentina de la \\
Mediana Empresa (CAME), la \\
Asociación de Comerciantes, \\
Industriales y Profesionales del \\
Partido de Hurlingham (ACIPH) y el| \\
Municipio de Hurlingham \\
Financiación: no especifica
\end{tabular} & $\begin{array}{c}\text { Establecer mejoras urbano- } \\
\text { comerciales que pongan en valor } \\
\text { al sector minorista revitalizando la } \\
\text { zona cétrica y sus locales. } \\
\text { Modernizar y adaptar el comercio } \\
\text { a las necesidades del consumidor } \\
\text { local mediante intervenciones } \\
\text { concretas. }\end{array}$ & $\begin{array}{l}\text { Obras de infraestructura en la ciudad que } \\
\text { permitan ampliar los servicios y mejorar } \\
\text { el tránsito, la seguridad y el espacio } \\
\text { público. }\end{array}$ & $\begin{array}{l}2017 \text { Se retiraron a los vendedores } \\
\text { ambulantes }\end{array}$ & No se encontró información & $\begin{array}{c}\text { No se encontró } \\
\text { información }\end{array}$ \\
\hline $\begin{array}{l}\text { Localidad. Loma } \\
\text { Hermosal EI } \\
\text { Libertador } \\
\text { (Tres de Febrero) }\end{array}$ & 2016 & \begin{tabular}{|c|} 
Calle $1^{\circ}$ de Mayo entre Rio \\
Cubay Ruta 8 \\
Total: 2 cuadras
\end{tabular} & $\begin{array}{c}\text { Municipio; Cámara de Comercio e } \\
\text { Industria local; Confederación } \\
\text { Afgentina de la Mediana Empresa } \\
\text { (CAME) y Federación Económica } \\
\text { de la Provincia de Buenos Aires } \\
\text { (FEBA) } \\
\text { Financiación: Municipio } \\
\end{array}$ & \begin{tabular}{|c|} 
Poner en valor del centro \\
comercial a cielo abierto de la calle \\
$1^{\circ}$ de Mayo y ruta 8 . \\
Potenciar el comercio y el \\
encuentro entre los vecinos.
\end{tabular} & \begin{tabular}{|} 
Ensanchamiento de la calzada, nuevas \\
veredas, iluminación y mobiliario (bancos \\
y cestos de eresidos). Construcción de \\
sumideros y el ordenamiento publicitario.
\end{tabular} & Etapa de proyecto & $\begin{array}{l}\text { Plan de cCCA para otras } \\
\text { localidades (*) }\end{array}$ & $\begin{array}{c}\text { No se encontró } \\
\text { información }\end{array}$ \\
\hline
\end{tabular}

$\left(^{\star}\right)$ Plaza Plate: peatonalización de las calles circundantes los fines de semana; Ciudad Jardín: corredor aeróbico que une Saenz Peña con Ciudad Jardín (instrumentos asociados) y promoción comercial; El Palomar: estado de proyecto/ Caseros: se crea la asociación de comerciantes de Caseros, formada por los comerciantes de las calles más importantes de la localidad/ Martín Coronado: estado de proyecto/ Pablo Podestá: estado de proyecto/ Sáenz Peña: corredor aeróbico que une Saenz Peña con Ciudad Jardín (instrumentos asociados) y eventos de promoción comercial/ Villa Bosch: promoción comercial- eventos especialmente- y pavimentación general para la localidad/ Villa Raffo: estado de proyecto/ Santos Lugares: promoción comercial/ Ciudadela: proyecto para calles Gaona y Rivadavia.

Tabla 1. Descripción de los Centros Comerciales a Cielo Abierto en el Conurbano Bonaerense (en proceso) Fuente: Elaboración propia 
La primera aproximación sobre el plano de distribución territorial de los 30 CCCA relevados en el CB (figura 1), da cuenta de una localización predominante en los municipios del corredor norte (San Fernando, San Isidro, Tigre, Vicente López) y noroeste (San Miguel, Hurlingham y Tres de Febrero -los dos últimos con iniciativas en fase de estudio o proyecto preliminar-). Las restantes cinco operaciones se ubican en partidos del eje oeste (Morón y Moreno) y sur (Lomas de Zamora). Esta distribución coincide en gran parte, con los sectores de nivel socioeconómico más altos del conurbano, que a su vez cuentan con la mayor dotación de equipamientos educativos, sanitarios, culturales, comerciales y deportivos de la región. Una lógica similar puede trasladarse al patrón de distribución territorial de las intervenciones en CABA, concentradas mayormente en la zona del microcentro y los barrios de Palermo y Villa Crespo, sectores que cuentan con unos de los valores del suelo más altos de la ciudad.

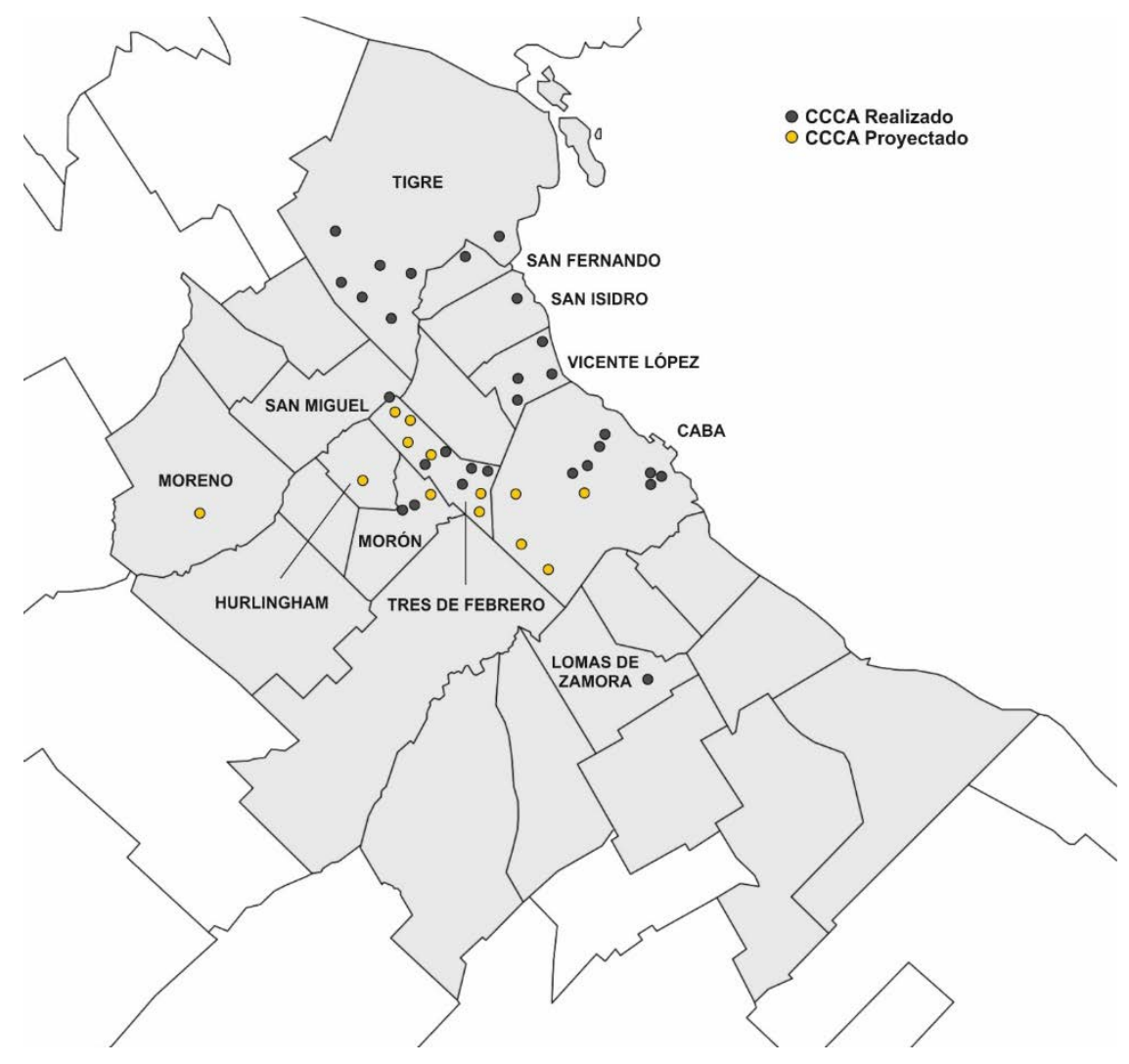

Figura 2. Intervenciones de CCCA en el Conurbano Bonaerense Fuente: Elaboración propia

Por su parte, los mapas de intervención por localidad -en los que se han seleccionado y esquematizado 10 de los 30 CCCA relevados- (figura 2) dan cuenta que la noción de centro, en general, aparece asociada a los sectores próximos a las estaciones ferroviarias, donde tradicionalmente se han concentrado las instituciones (iglesia, plaza, sede municipal) y donde se encuentra también el comercio popular. La mayor parte de los CCCA ejecutados se despliegan sobre una o dos de las calles con más dinamismo comercial, en una extensión que varía desde dos a diez cuadras. La única excepción es la localidad de Morón, en donde el lugar objeto del convenio -no así de la actuación realizada- se compone de 21 manzanas.

Además, en nueve de las diez localidades seleccionadas se ha intervenido en un solo sector urbano, siendo Don Torcuato la única que cuenta con múltiples intervenciones, bajo una idea sistémica o de policentralidades, lo cual se replica a nivel de partido (las acciones no se concentran sólo en la ciudad cabecera sino también en otras cinco localidades). Algo similar ocurre en el partido de Tres de Febrero que cuenta con once estudios o propuestas de intervención, tres de ellas en la localidad de El Palomar.

El redibujo de estas operaciones denota, asimismo, las limitaciones que supone su formulación a nivel local, debiendo circunscribirse al ejido municipal, situación que muchas veces no se condice con el desarrollo de las centralidades en el CB, que por su propia fisonomía continua tienden a superarlos límites políticoadministrativos. Un ejemplo de ello es el caso de San Fernando, cuya intervención culmina exactamente en el límite con el partido de Tigre, junto a una gran superficie comercial. El CCCA de San Miguel -nodo atractor 
de municipios vecinos como José C. Paz y Malvinas Argentinas-, se presenta como la única excepción a los otros casos, excediendo su área de intervención -aunque dentro del mismo partido- sobre la localidad contigua de Muñiz, estableciendo el punto de culminación en la Plaza de las Carretas. La concentración de oferta de comercios y servicios en este sector ${ }^{13}$ probablemente está asociada a que, hasta 1995, San Miguel fue cabecera del antiguo partido General Sarmiento, actualmente desmembrado en José C. Paz y Malvinas Argentinas. En este sentido, la historia de las subdivisiones municipales (por ejemplo, Hurlingham como parte Morón, o Tres de Febrero, antes perteneciente al partido de San Martín) se relaciona con el mayor o menor peso -así como el carácter múltiple- de las centralidades objeto de análisis.

Por otro lado, la información recabada arroja que estos proyectos, por cuestiones económicas y/o de coyuntura política, se desarrollan en diferentes etapas lo que implica, muchas veces, el transcurso de varios años para su completa ejecución. Como los convenios firmados supeditan el financiamiento de los proyectos a los gobiernos locales, sin una entidad independiente para la gerencia del proyecto de CCCA, ${ }^{14}$ esto se presenta a veces como una dificultad al momento de generar continuidad en las políticas de intervención. Sin embargo, estas cuestiones no han impedido que localidades como San Fernando hayan concretado completamente los objetivos establecidos en su convenio, y que incluso, decidieran extender el área de intervención. Como se mencionó anteriormente, el CCCA de San Miguel se presenta, en este sentido, como un caso de gestión singular, ya que es el único del cual surgió un ente especifico de control, el "Consorcio Asociativo Paseo San Miguel", responsable del mantenimiento y la promoción del centro, e incluso, de fijar una cuota para los comercios del área involucrada, lo que supone un punto de contacto con los casos de referencia estudiados. ${ }^{15}$

En relación a la vinculación con otros instrumentos urbanísticos, si bien algunas intervenciones de CCCA se inscriben en el marco de planes urbanos a escala municipal (ej. Morón, San Fernando, Moreno), no suelen aparecer integradas con el resto de políticas públicas sectoriales -en materia de movilidad, manejo de residuos, vivienda social, e incluso de espacio público-; así como también se observan muy escasas articulaciones con otros sectores de intervención urbana del mismo u otro municipio.

Por ejemplo, en relación a las políticas de transporte, se puede mencionar el caso del centro de Lomas de Zamora, localidad muy convocante durante los fines de semana, debido a la importante revitalización del comercio de calle en la zona apodada "Las Lomitas" -contigua al centro tradicional- y después de las tareas de mejora de la peatonal Laprida, donde la accesibilidad desde el transporte público y privado, la problemática del estacionamiento en playas o en vía pública, reordenamientos de las líneas de buses y acondicionamiento de paradas, etc., han quedado relegadas frente a la búsqueda de una "imagen" unitaria del centro como factor de atracción comercial (Vecslir, y otros, 2016). ${ }^{16}$

Como contrapunto a ese ejemplo, el CCCA de Morón es de los pocos casos que se integran en un proyecto para el fortalecimiento del área central, basado en intervenciones en el espacio público como estructurante de sus áreas funcionales y simbólicas (institucional, cultural y judicial), y los ejes comerciales que las vinculan. Si bien los proyectos CCCA y Plaza La Roche tienen su origen a comienzos de la década de los 2000 cuando todavía el municipio no contaba con un marco amplio de planificación, en el año 2005 se presentó el Plan Estratégico 2020 en el que ambas intervenciones aparecen vinculadas a otras actuaciones, e inscriptas dentro del proyecto Área Central de Morón, y a éste dentro del programa Área Centrales (Bustos, Colella, \& Da Representacao, 2010).

Aunque, en general, tampoco se vislumbran estudios o planes que pongan en relación los CCCA con políticas territoriales más bastas, existen algunos convenios recientes como el "Plan D", que evidencian la voluntad asociativa de municipios, en este caso de la zona norte (Vicente López, San Isidro, San Fernando y Tigre), con el objetivo de coordinar políticas y acciones gubernamentales para reforzar la potencialidad económica y social de un sector de la región metropolitana, superando los límites municipales.

\footnotetext{
${ }^{13}$ Para mayor información acerca del proceso de densificación y verticalización residencial, así como de las intervenciones públicas en el Microcentro de San Miguel, ver (Muñoz, 2014)

${ }^{14}$ Existe la figura del gerente urbano en CABA y en provincias del interior del país.

${ }^{15}$ En diciembre de 2012 se firmó entre la Municipalidad de San Miguel y la Cámara de Comercio local una carta de intención para trabajar en conjunto en el desarrollo de este, extendiendo el radio de influencia del Paseo San Miguel más allá de la Av. Perón hasta Maestro D'Elía, Paunero y Sarmiento entre J.A. Roca y Conesa (Muñoz, 2014).

${ }^{16}$ En el trabajo citado, tanto en las opiniones de las personas encuestadas en calle, como en las entrevistas realizadas a los responsables de estas políticas en Lomas de Zamora, el tema de la movilidad fue señalado como una problemática pendiente, reflejada en la poca frecuencia de algunas líneas de transporte público, la dificultad de acceso al centro y el colapso de tránsito y falta de estacionamientos durante los fines de semana, entre otros. También se mencionaron problemas vinculados a la recolección basura, e insuficiencia de infraestructura (especialmente energética) frente al desarrollo comercial y los nuevos edificios en altura.
} 

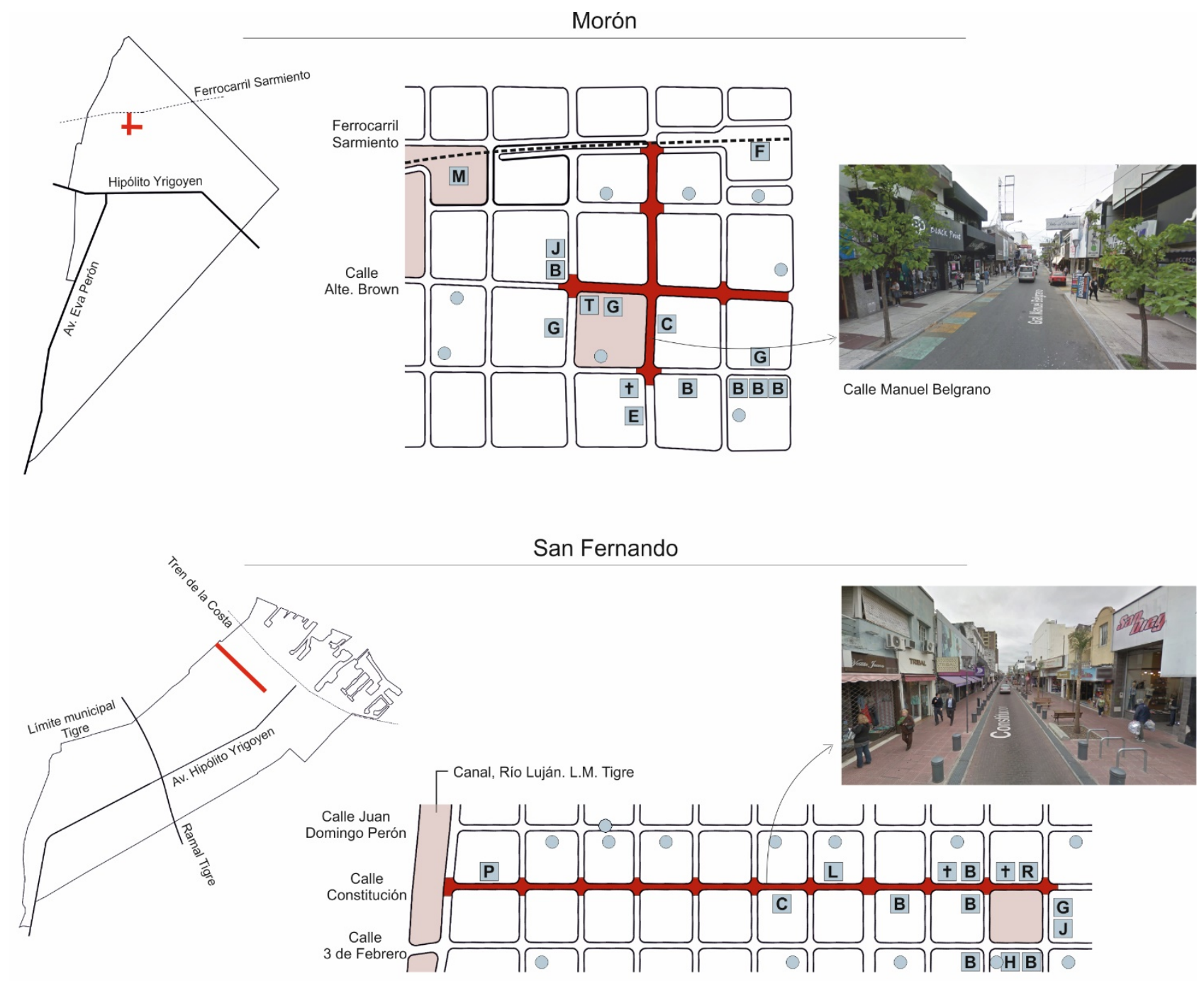

Don Torcuato (Tigre)


Figura 3. Esquemas de las intervenciones de CCCA por localidad- Parte I

Fuente: Elaboración propia 


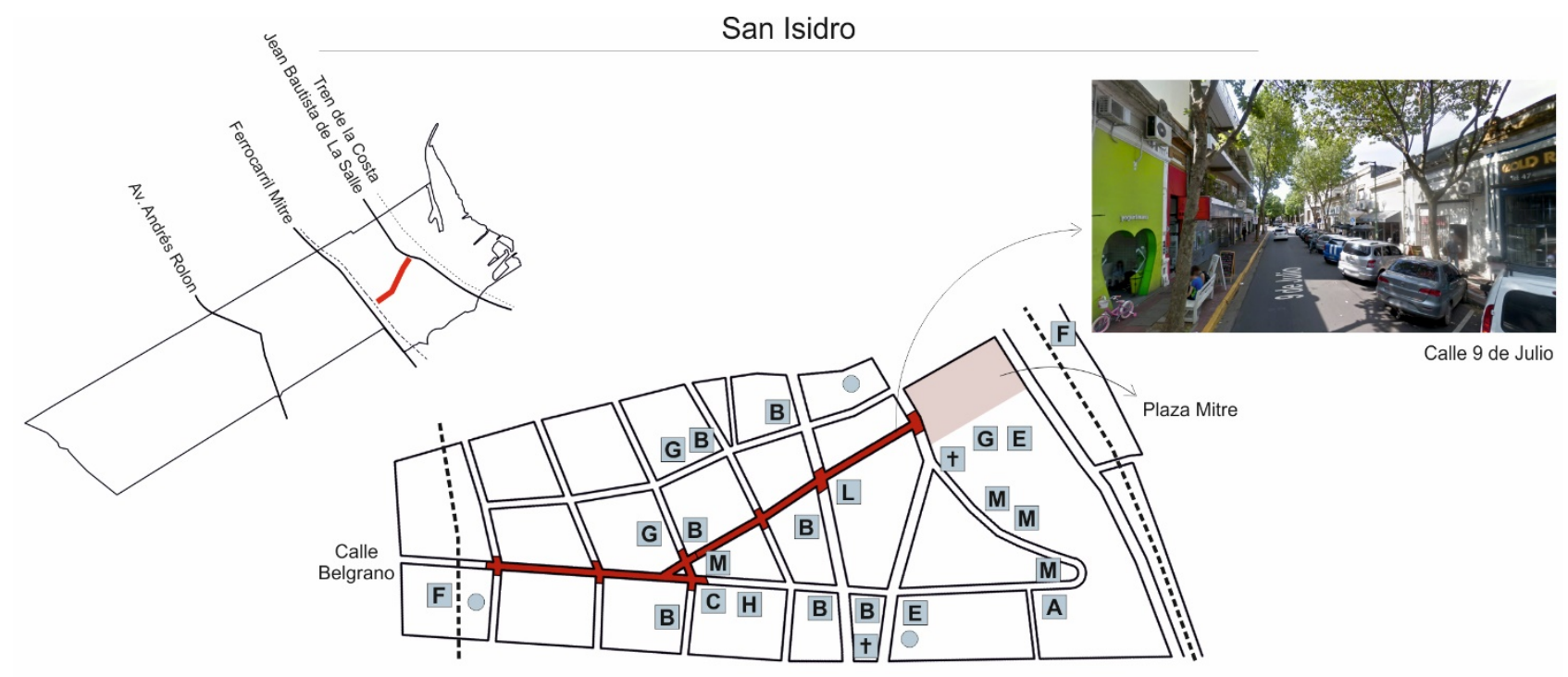

San Miguel

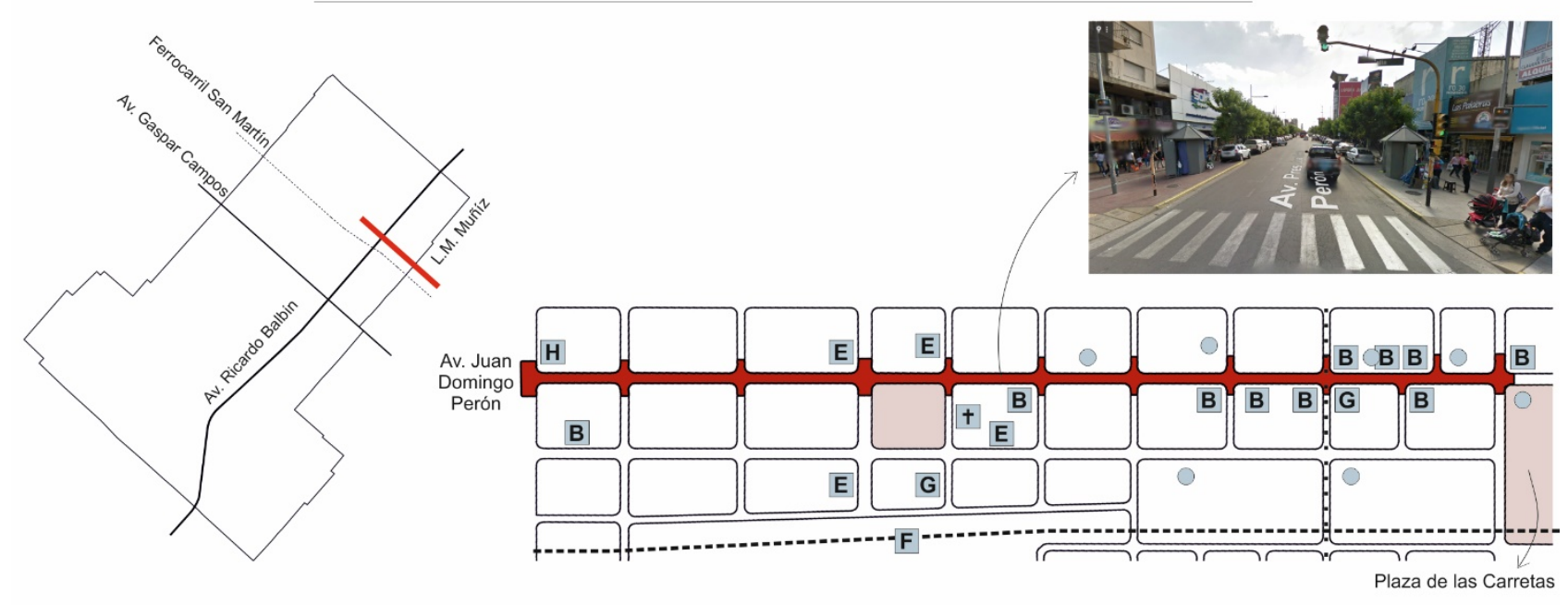

Lomas de Zamora


\section{REFERENCIAS}

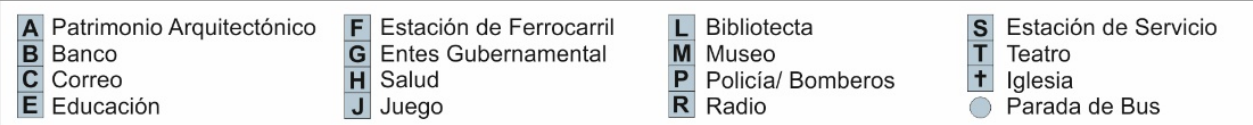

Figura 3. Esquemas de las intervenciones de CCCA por localidad- Parte II

Fuente: Elaboración propia 
Munro (Vicente López)
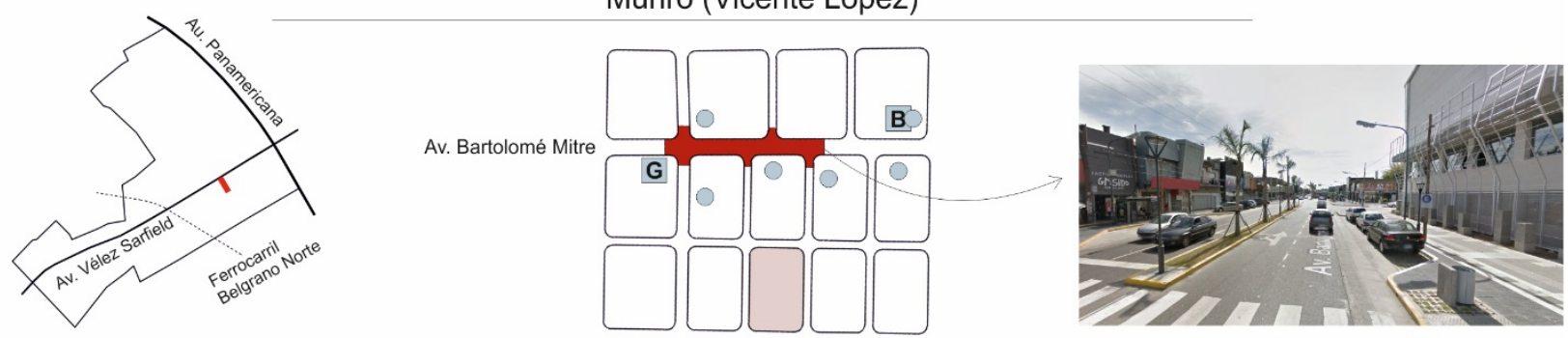

Moreno
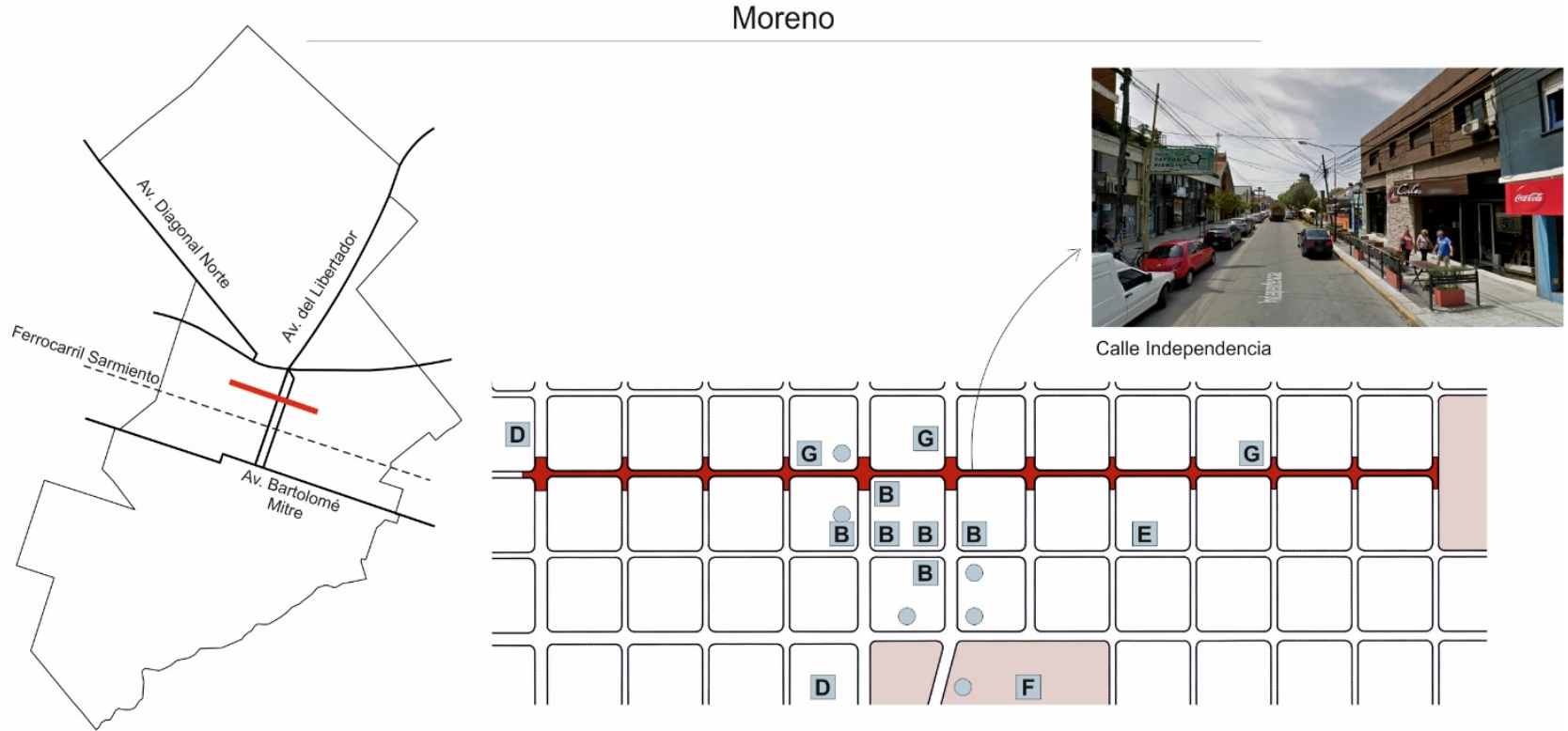

Hurlingham
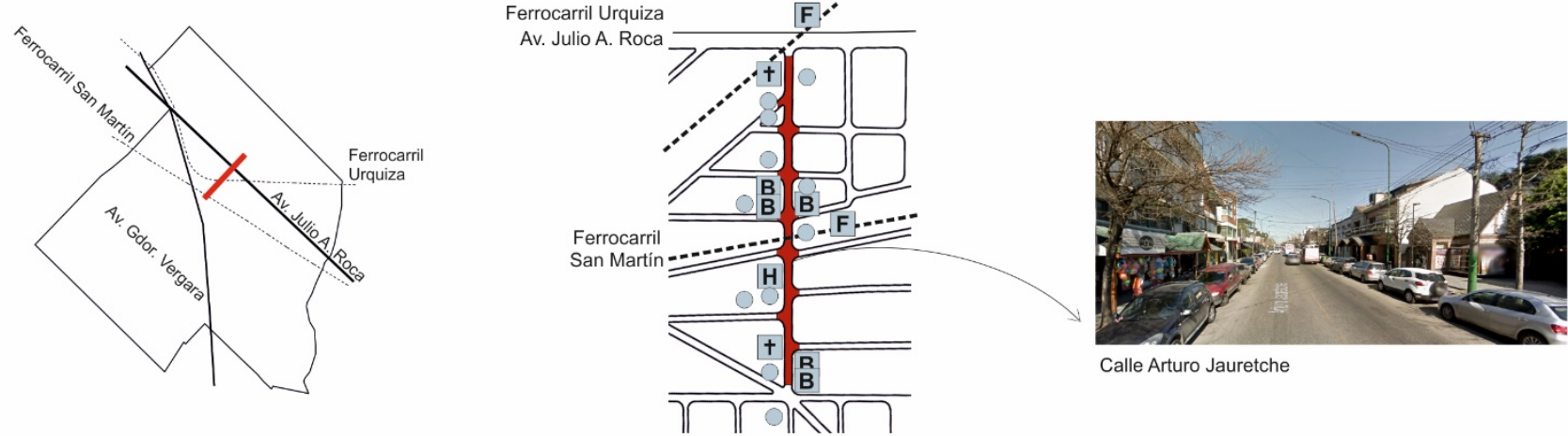

Loma Hermosa (Tres de Febrero)
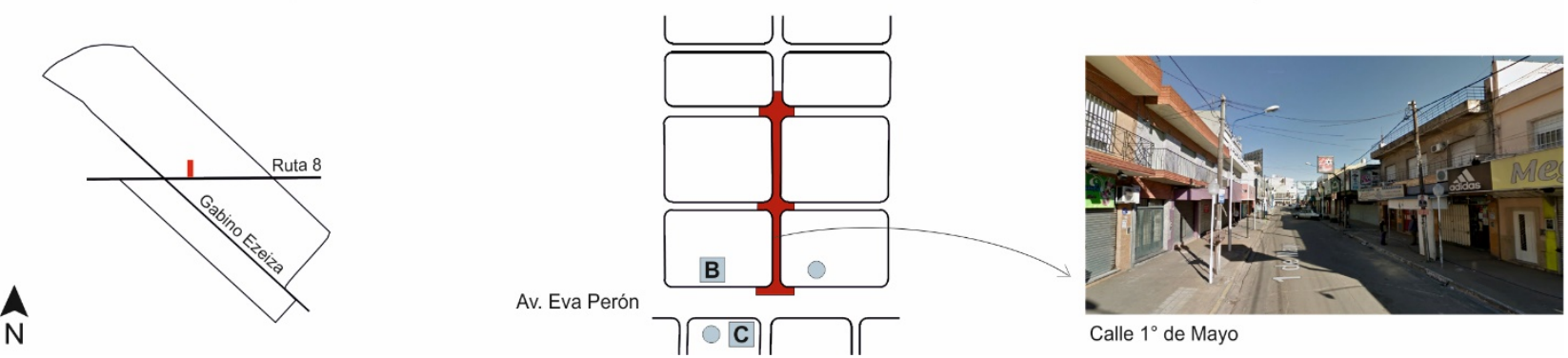

Figura 3. Esquemas de las intervenciones de CCCA por localidad- Parte III Fuente: Elaboración propia 
Particularmente, los objetivos planteados desde los diferentes convenios se orientan a generar mejores condiciones de competitividad para los comercios involucrados, poniendo en valor la identidad del sector a partir de determinadas acciones de renovación o reacondicionamiento del área urbana (figura 3). Sin embargo, aunque el argumento de la valorización identitaria supondría acciones específicas que respondan a la idiosincrasia de cada localidad, lo cierto es que estas son muy semejantes en todos los casos estudiados. Podemos ordenar estas acciones en tres categorías:

- Infraestructura: ensanchamiento de veredas y/o igualación del nivel de las mismas con el nivel de la calle, nuevas dársenas para estacionamiento, soterramiento del cableado eléctrico y nuevos desagües pluviales.

- Equipamiento urbano y materialidad: incorporación de nuevos pavimentos, luminarias, cestos de residuos y espacios de permanencia; preservación o propuesta de arbolado urbano; pintado de sendas peatonales y carriles vehiculares.

- Señalética y cartelería comercial: reemplazo de la señalética existente por una con estética gráfica unificada, facilitando la identificación del centro, su localización desde las arterias principales y la ubicación de locales y marcas; eliminación de la publicidad urbana (carteles bandera, marquesinas, pasacalles); alineación de las marquesinas y regulación de la cartelería comercial según las normativas municipales.


Figura 4. Cuatro operaciones de CCCA en el espacio público: San Fernando, Morón, San Isidro, y Lomas de Zamora Fuentes: (Que Pasa, 2015); (Confederación Argentina de la Mediana Empresa, s.f.); (Plataforma Arquitectura, 2014); (Confederación Argentina de la Mediana Empresa, 2013).

Se trata, en general, de tareas orientadas a eliminar la "contaminación visual" y dar "identidad" al sector, respondiendo a cuestiones estéticas más que funcionales. En este sentido, la propuesta del mismo tipo de intervenciones en los diferentes contextos analizados arroja algunos interrogantes: ¿cómo se relacionan las obras de mejora con el rescate identitario buscado? E incluso, ¿cuál es la identidad que quiere revalorizarse?

Para ejemplificar esta cuestión, podemos citar el caso de Munro. La emblemática Avenida Mitre, supo ser conocida como "la meca del jean" entre los años '70 y '80, cuya concentración de outlets atraía a personas a nivel regional. Sin embargo, aunque desde los objetivos planteados para el convenio de CCCA se reconoce esta importante tradición comercial, no se explica su correlato con las tareas que se van a desarrollar, ni cómo diferenciar el tratamiento de un corredor especializado de estas características respecto de un centro urbano histórico o institucional.

Por otro lado, iniciativas recientes como la de la localidad de Hurlingham, concentraron sus primeras acciones en quitar la venta ambulante del sector, siendo su erradicación una de las políticas básicas impulsadas por la CAME. Bajo el lema de "recuperar la calle", se soslaya el significado social, económico e incluso simbólico que este tipo de comercio construye en el espacio urbano, acompañando -en el mejor de los casos- la propuesta de su relocalización en "ferias oficializadas", ${ }^{17}$ con el fin de incorporar, paulatinamente la venta ambulante al comercio formal.

En el marco de esta discusión, cabe citar, por último, el caso de San Isidro donde el proyecto ganador de un concurso de ideas para la renovación del centro histórico de la ciudad y, por tanto, de su área comercial, se propuso reforzar la identidad "verde", el equilibrio entre ciudad y naturaleza que caracteriza al municipio. ${ }^{18}$

\footnotetext{
${ }^{17}$ Como ejemplo, la CAME cita el municipio de Vicente López, donde la "saladita" ubicada en las calles Vélez Sarsfield y Av. Mitre se regularizó, aunque advierte que esto solo significa "un leve avance para el distrito", y que igualmente la Av. Mitre sigue invadida por vendedores ambulantes. (http://www.redcame.org.ar/contenidos/comunicado/Crecio-La-Venta-llegal-En-La-Argentina.994.html)

${ }^{18} \mathrm{El}$ Concurso Nacional de ideas para la Renovación urbana del centro de San Isidro fue convocado en el 2013 por el Colegio de Arquitectos de la provincia de Buenos Aires (CAPBA), la Municipalidad de San Isidro, la Cámara de Comercio y la CAME.
} 
Esta propuesta representa así, el único caso en el que se explicita qué valores urbanos -aunque limitados a los aspectos físicos- pretenden enfatizarse y a través de qué acciones. En este caso, se busca resolver los déficits encontrados en áreas de mayor densidad mediante una normativa de incorporación de vegetación que, combinada con la normativa publicitaria, defina incentivos y premios para direccionar la iniciativa privada. Destaca, asimismo, como singularidad, la propuesta de estacionamientos subterráneos y de incorporación de vegetación autóctona, toldos verdes y luminaria tubular curvada en la urbanización del espacio público.
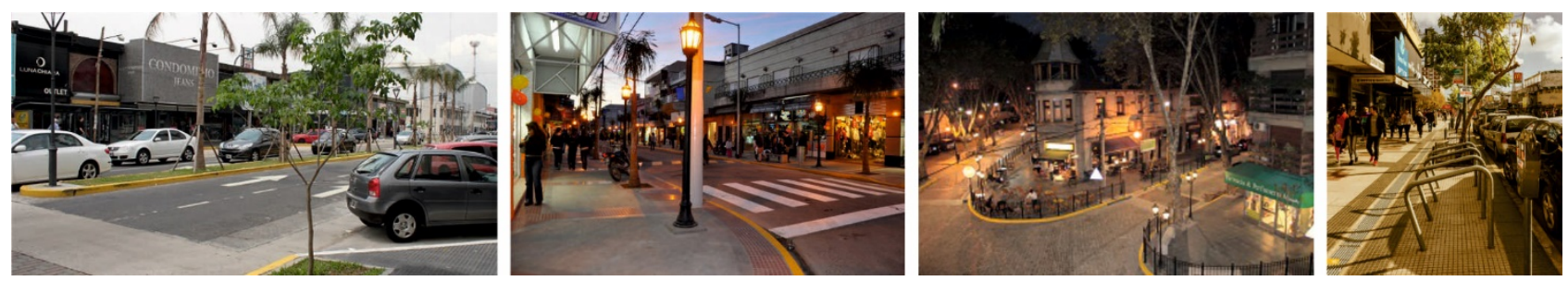

Figura 5. Cuatro operaciones de CCCA en el espacio público: Munro, Don Torcuato, Bajo de Vicente López y San Miguel Fuentes: (Vivamos Vicente López, 2014); (Confederación Argentina de la Mediana Empresa, 2013); (Vivamos Vicente López, 2013); (Confederación Argentina de la Mediana Empresa, 2015).

\section{CONSIDERACIONES FINALES Y NUEVOS EJES DE DEBATE}

Los casos expuestos en este trabajo presentan cómo el modelo de CCCA es incorporado en el CB. Son variados los ejes de discusión que su análisis aporta, sin embargo, centraremos la reflexión en tres temas principales y, en relación a ellos, la contradicción que surge entre los objetivos que plantean, muchas veces sesgados por los intereses de ciertos actores, en correspondencia con las acciones que se llevan a cabo para conseguirlos.

El primer eje de discusión surge en relación a las diferencias que plantean los modelos de CCCA estudiados como antecedentes y sus traducciones locales. Una de las más notorias, es la ausencia de entes de gerenciamiento que, en contraposición a las experiencias españolas, compromete, en muchos casos, la continuidad de las políticas promovidas por los convenios. Debido a que el financiamiento y posterior responsabilidad de gestión recae casi exclusivamente en los gobiernos locales, éstos quedan supeditados a los vaivenes económicos y/o voluntades políticas. Por otro lado, el declive que sufren los centros urbanos de referencia -especialmente en EUA-, no es una situación análoga a la de los ejemplos locales que, tal como se expuso en éste y anteriores trabajos (Vecslir \& Blanco, 2014; Ciccolella, Vecslir, \& Baer, 2015), aun con signos de deterioro ambiental, conservan gran dinamismo comercial, o incluso se han revitalizado y extendido "vía mercado" junto a recientes procesos recientes de verticalización residencial (ej. Lomas de Zamora, San Miguel, Tigre centro, Vicente López, etc.).

Así mismo, la lógica de intervención en los municipios del CB asocia las acciones en el centro fundamentalmente al espacio público y el equipamiento, y en la periferia a la infraestructura y la vivienda social (Bustos, Colella, \& Da Representacao, 2010); esta dicotomía no parece comulgar con los objetivos de hibridez funcional e inclusión social de algunos antecedentes de los CCCA, así como tampoco parece corresponderse con las nuevas configuraciones metropolitanas de límites difusos. Esto nos lleva a preguntarnos: ¿es entonces la motivación principal del CCCA configurarse en nuestro contexto como un instrumento en contra del shopping y las "saladitas"? ¿O es más bien un instrumento que refuerza un tipo de centralidad específica (la tradicional) beneficiando a cierto grupo de actores, actuando por lo tanto, de manera análoga al shopping?

De este aspecto, deriva en el segundo tema de debate que planteamos, en torno a la noción de centralidad y a las diferentes formas y procesos que la caracterizan en el CB. Al objetivo de revitalización de las "centralidades históricas", desarrolladas en torno a las estaciones ferroviarias, como lugares de concentración institucional, del comercio cotidiano, los servicios y el espacio público tradicional; los convenios de CCCA contraponen el surgimiento y competencia de las "nuevas centralidades" periféricas, en forma de enclaves aislados del ocio y el consumo. Sin embargo, la existencia de corredores con gran dinamismo económico a lo largo rutas, ejes ferroviarios, avenidas y demás formas de concentración lineal, que atraviesan uno o varios partidos del CB, nos habla de otras configuraciones de la centralidad, no contempladas por los CCCA -ni en general por los instrumentos de planificación vigentes- (Vecslir \& Elimbaum, 2016). Las intervenciones 
analizadas continúan concibiendo la centralidad de la manera tradicional, y se desarrollan, en casi todos los casos, dentro de los límites político-administrativos, ignorando la continuidad física y funcional que muchos ejes comerciales presentan entre localidades del mismo u otros municipios de la región metropolitana.

Claro que contemplar estas centralidades lineales, supondría cierta sofisticación de los instrumentos urbanísticos empleados, al considerar proyectos de carácter supramunicipal. Sin embargo, como también se ha analizado, estos instrumentos no son solo posibles de materializarse, sino que de hecho se están intentando llevar a cabo desde los municipios del corredor norte a través del ya mencionado "Plan D". Este tipo de alianzas territoriales no solo permite contemplar las operaciones de CCCA en relación con políticas más amplias de movilidad y accesibilidad desde el transporte público, sino que también abre la discusión en torno de las competencias y complementariedades del sistema de centralidades a escala de toda la región metropolitana.

Finalmente, el tercer eje de debate, tiene que ver con el tema del rescate identitario. Como planteábamos en el punto anterior, en la mayoría de los casos analizados no queda en claro cuál es la identidad que quiere valorizarse a partir de las diferentes acciones de intervención. Tampoco parece existir una discusión sobre cuáles son los rasgos característicos de cada localidad. La ausencia de estas reflexiones parece traer aparejadas nuevas contradicciones entre los objetivos que se plantean y las acciones que se llevan a cabo.

Por un lado, la expulsión de la venta ambulante, una forma de comercialización muy extendida en nuestra región metropolitana, que es vista como una amenaza para el comercio de calle. Se trata de una política de erradicación, que se manifiesta incluso con más fuerza en la ciudad capital, que en el último tiempo ha establecido importantes medidas de desalojo de los manteros en diferentes barrios como Once o Retiro. Aunque escapa al presente trabajo, la ausencia de una reflexión sobre su rol como parte de la idiosincrasia de muchos centros urbanos, la complementariedad de algunos productos comercializados y la repercusión para la animación peatonal que suponen, así como las propuestas de reubicación en predios cerrados aislados de los principales ejes comerciales, lleva a cuestionarnos sobre los intereses que subyacen a estas políticas de mejoramiento urbano.

Por el otro, no parece existir un análisis sobre los efectos que la "estetización" del espacio urbano puede acarrear para las formas de comercio tradicional. El aumento de valor en la renta y la asistencia de un público con mayores ingresos económicos, consecuencias de estas acciones, trae aparejado la boutiquización y el recambio del tipo de comercio local. Informes de CAME expresan que aunque las ventas aumentan, al nuevo CCCA concurre también población con niveles de ingresos más altos, a lo que también se suma el encarecimiento en el valor de los alquileres, producto del aumento del valor de los inmuebles.

En un reciente artículo publicado en la página web de FCCA, se exponían los beneficios de las intervenciones de CCCA en Barcelona y New York, comentando que ahora "los clientes entran y salen de restaurantes, vinerías, salones de belleza y tiendas de ropa" y que esos resultados "confirman la necesidad impostergable de recuperar las calles para las personas. No sólo en beneficio del sector comercial, sino también para poner en valor las prácticas sociales que mantienen vivas nuestras ciudades" (Federación de Centros Comerciales a Cielo Abierto, Cascos Urbanos y Centros Históricos, 2016). Estas cuestiones ponen de manifiesto el riesgo de la adopción de modelos de gestión desarrollados en otros contextos geográficos, sin ponderar sus diferencias con las de la realidad local. El principal problema de la transferencia de políticas sin una reformulación previa, recae en las contradicciones que su aplicación produce en relación a los objetivos que se persiguen. Principalmente cómo se articula la cuestión identitaria (ciudadana y comercial) en las propuestas de mejoramiento urbano.

Sin dudas, las acciones de mejoramiento de los centros urbanos dotan a sus comercios de herramientas para competir con otros formatos, generan lugares atractivos para el público visitante y dinamizan el mercado del suelo. Sin embargo, debemos preguntarnos si con este fin, no se terminan por generar nuevos espacios de exclusión, semejantes a las superficies comerciales contra las que se quiere competir. 


\section{BIBLIOGRAFÍA}

ASOCIACIÓN PROVINCIAL DE EMPRESARIOS DE COMERCIO DE HUELVA (2000). I Congreso Nacional de Centros Comerciales Abiertos. La Trastienda, IV(4).

BRATOS MARTÍN, M. (2013). Business Improvement Districts: Una nueva forma de colaboración públicoprivada para la revitalización socioeconómica de áreas urbanas. Política y Sociedad 50 (1), 269-304.

BUSTOS, W., COLELLA, V. y DA REPRESENTACAO, N. (2010). Los centros tradicionales en la agenda política. Intervenciones en el espacio público. VI Jornadas de Sociología de la UNLP. La Plata.

CAME, CONFEDERACIÓN ARGENTINA DE LA MEDIANA EMPRESA (2016). Centros Comerciales Abiertos. 15 años. 100 ciudades. Buenos Aires: Revista Comerciar, Edición especial.

CARRIÓN, F. (Ed.) (2001). Centros Históricos de América Latina y El Caribe, Ed. UNESCO-BID- FLACSO, Quito.

CARRIÓN, F. (2005). La internacionalización de los centros históricos. Vivienda Popular, 16, 73-75,.

Carrión, Fernando (2007). Financiamiento de los centros históricos de América Latina y El Caribe. (S. E. FLACSO, \& L. I. Policy, Edits.) Quito.

CICCOLELLA, P., VECSLIR, L. y BAER, L. (2015). Revitalización de subcentros metropolitanos. Buenos Aires entre la ciudad dispersa y la ciudad compacta. Contexto, Revista de la Facultad de Arquitectura de la Universidad Autónoma de Nuevo León 11, 11-28.

HOYT, L. (2006). Importing Ideas: The Transnational Transfer of Urban Revitalization Policy. Intl Journal of Public Administration(29), 221-243.

HOYT, L. y GOPAL-AGGE, D. (2007). The Business Improvement District Model: A Balanced Review of Contemporary Debates. Geography Compass, 1(4), 946-958.

JACOBS, J. (1961). The Death and Life of Great American Cities. New York: Random House.

Ludueña, Wiley (2002). Lima: poder, centro y centralidad. Del centro nativo al centro neoliberal. EURE, Revista latinoamericana de estudios urbano regionales 28(83), 45-65.

LORENZEN MARTINY, M. (2015). ¿La gentrificación rural y urbana como factor de anclaje de la población originaria? indicios desde Morelos, México. En V. Delgadillo, I. Díaz, \& L. Salinas, Perspectivas del estudio de la gentrificación en México y América latina (275-300). México: geografía para el Siglo XXI.

MITCHELL, J. (2001). Business Improvement Districts and the "New" Revitalization of Downtown. Economis Development Quarterly, 15(2), 115-123.

MOLINILLO JIMENEZ, S. (2001). Centros comerciales de área urbana. Estudio de las principales experiencias extranjeras. Distribución y Consumo 57 (27-45).

MUÑOZ, M. (2014). Las torres en el damero: Transformaciones residenciales en una centralidad de la segunda corona de la RMBA. Los Polvorines: Tesis de Licenciatura en Urbanismo, Instituto del Conurbano, Universidad Nacional de General Sarmiento.

VECSLIR, L. y BLANCO, J. (2014). Movilidad cotidiana y reestructuración de la centralidad en el sur de la Región Metropolitana de Buenos Aires. XIII Seminario Internacional: Red Iberoamericana de Investigadores sobre Globalización y Territorio (RII). Salvador (Brasil).

VECSLIR, L. y ELIMBAUM, P. (2016). Centro y centralidades en la Región Metropolitana de Buenos Aires. En C. Jaimes [et al.]; comp. F. Janches [et al.] Del conocimiento al desarrollo: nuevos desafíos de la universidad en la gestión del desarrollo urbano contemporáneo. 1a ed. Ciudad Autónoma de Buenos Aires: Eudeba, pp. 420-439

VECSLIR, L., BLANCO, J., NEROME, M., SCIUTTO, F., MAESTROJUAN, P. y RODRIGUEZ, L. (2016). Movilidad, centralidad y políticas públicas en el sur de la Región Metropolitana de Buenos Aires. XIV Seminario Internacional de la RII. Monterrey (México). 


\section{Fuentes electrónicas}

ÁREAS GLOBALES. (2015). Los locales a cielo abierto concentran el 75\% de las ventas. Recuperado de <http://www.areas-digital.com.ar/nota.php?id=24369> (Consulta: 01/02/2017).

CONFEDERACIÓN ARGENTINA DE LA MEDIANA EMPRESA. (2013). CAME participó de la inauguración de la peatonal Laprida. [Figura 4] Recuperado de < http://www.redcame.org.ar/contenidos/circular/CAMEparticipo-de-la-inauguracion-de-la-peatonal-Laprida.4316.html> (Consulta: 8/03/2017).

CONFEDERACIÓN ARGENTINA DE LA MEDIANA EMPRESA. (2013). Creció la venta ilegal en la Argentina. Recuperado de <http://www.redcame.org.ar/contenidos/comunicado/Crecio-La-Venta-Ilegal-En-LaArgentina.994.html> (Consulta: 20/11/2016).

CONFEDERACIÓN ARGENTINA DE LA MEDIANA EMPRESA. (2006). Jornada de evaluación del programa de fortalecimiento al comercio minorista convenio CAME-BID-FOMIN. Recuperado de <http://www.redcame.org.ar/contenidos/circular/Jornada-de-evaluacion-del-Programa-de-Fortalecimiento-alComercio-Minorista-convenio-CAME-BID-FOMIN.425.html> (Consulta: 20/11/2016).

CONFEDERACIÓN ARGENTINA DE LA MEDIANA EMPRESA. (s.f.). Centro Comercial a Cielo Abierto de Morón. [Figura 4] Recuperado de <http://redcame.org.ar/adjuntos/ANEXO\%20\%20CAME\%20en\%20la\%20Inauguracion\%20del\%20CCCA\%20Moron.pdf> (Consulta: 04/11/2016).

FEDERACIÓN DE CENTROS COMERCIALES A CIELO ABIERTO, CASCOS URBANOS Y CENTROS HISTÓRICOS. (2016). Los autos no hacen compras, la gente sí. Recuperado de <http://www.fccca.com.ar/noticias.php?idNot=447> (Consulta: 12/11/2016).

PASEOS DE BUENOS AIRES. (s.f.) Recuperado de <http://www.paseosdebuenosaires.com.ar/> (Consulta: 09/02/2017).

MUNICIPIO TIGRE. (2011). Massa inauguró un renovado centro comercial en Don Torcuato. [Figura 5] Recuperado de: <https://www.facebook.com/notes/municipio-de-tigre/massa-inaugur\%C3\%B3-un-renovadocentro-comercial-en-don-torcuato/10150603210875307/> (Consulta: 08/03/2017).

PLATAFORMA ARQUITECTURA. (2014). Primer Lugar Concurso Nacional de Ideas para la Renovación urbana del área centro de San Isidro/ Argentina. [Figura 4] Recuperado de <http://www.plataformaarquitectura.cl/cl/02-344342/primer-lugar-concurso-nacional-de-ideas-para-larenovacion-urbana-del-area-centro-de-san-isidro-argentina> (Consulta: 01/02/2017).

QUE PASA: NOTICIAS, OPINIÓN Y CULTURA DE LA ZONA NORTE. (2015) La calle Constitución de San Fernando seguirá como peatonal este jueves 24. [Figura 4] Recuperado de <http://quepasaweb.com.ar/lacalle-constitucion-de-san-fernando-seguira-como-peatonal-este-jueves-24/> (Consulta: 09/02/2017).

VIVAMOS VICENTE LÓPEZ. (2013). El Centro Comercial del bajo de Vicente López luce renovado y puesto en valor. [Figura 5] Recuperado de: <http://www.vicentelopez.gov.ar/noticias/el-centro-comercial-del-bajo-devicente-lopez-luce-renovado-y-puesto-en-valor-2> (Consulta: 08/03/2017).

VIVAMOS VICENTE LÓPEZ. (2014). El Centro Comercial Munro ya luce renovado. [Figura 5] Recuperado de: <http://www.vicentelopez.gov.ar/noticias/el-centro-comercial-munro-ya-luce-renovado> (Consulta: 08/03/2017). 